\title{
Majority of never-smokers with airflow limitation do not have asthma: the Copenhagen General Population Study
}

\author{
Yunus Çolak, 1,2,3,4 Shoaib Afzal, 3,4,5 Børge G Nordestgaard, 3,4,5 Peter Lange 2,3,4,5,6
}

- Additional material is published online only. To view please visit the journal online (http://dx.doi.org/10.1136/ thoraxjn-2015-208178).

${ }^{1}$ Department of Internal Medicine, Section of Respiratory Medicine, Herlev and Gentofte Hospital, Copenhagen University Hospital, Herlev, Denmark ${ }^{2}$ Department of Public Health, Section of Social Medicine, University of Copenhagen, Copenhagen, Denmark

${ }^{3}$ The Copenhagen General Population Study, Herlev and Gentofte Hospital, Copenhagen University Hospital, Herlev Denmark

${ }^{4}$ Faculty of Health and Medical Sciences, University of Copenhagen, Copenhagen, Denmark

${ }^{5}$ Department of Clinical Biochemistry, Herlev and Gentofte Hospital, Copenhagen University Hospital, Herlev, Denmark

${ }^{6}$ Medical Unit, Respiratory Section, Hvidovre Hospital Copenhagen University Hospital, Hvidovre, Denmark

\section{Correspondence to} Professor Peter Lange, Professor and Consultant in Respiratory Medicine, Department of Public Health, Section of Social Medicine, University of Copenhagen Øster Farimagsgade 5 , PO Box 2099, Copenhagen $\mathrm{K}$ DK-1015, Denmark; Peter.Lange@sund.ku.dk

Received 10 December 2015 Revised 8 February 2016 Accepted 23 February 2016 Published Online First 25 March 2016

\section{ABSTRACT \\ Background A substantial proportion of individuals with airflow limitation are never-smokers. However,} whether never-smokers with airflow limitation have undiagnosed asthma is unknown. We hypothesised that the majority of never-smokers with respiratory symptoms and airflow limitation but without known asthma have undiagnosed asthma by comparing characteristics and prognosis in never-smokers with airflow limitation and asthma (NS+AFL+A) with never-smokers with airflow limitation but without asthma (NS+AFL-A).

Methods Among 94079 participants aged 20-100 years from the general population, 39102 (42\%) were never-smokers. In this group, 13719 (35\%) reported to have respiratory symptoms of whom 1610 $(12 \%)$ had airflow limitation. We investigated characteristics and risk of complications (asthma or COPD exacerbations, pneumonias and all-cause mortality) and comorbidities (lung cancer, ischaemic heart disease, myocardial infarction, deep venous thrombosis and PE) during 4.5 years median follow-up.

Results NS+AFL-A compared with NS+AFL+A reported less allergy and respiratory symptoms, and had higher $\mathrm{FEV}_{1}$ and lower levels of eosinophils and IgE in peripheral blood. NS+AFL+A had increased risk of asthma and COPD exacerbations, but not of pneumonias; adjusted HRs in NS+AFL+A compared with NS+AFL-A were $16(95 \% \mathrm{Cl} 3.7$ to 73$)$ for asthma exacerbations and 15 (2.8 to 80) for COPD exacerbations. Still, NS+AFL $-A$ had increased risk of COPD exacerbations and pneumonias, but not of asthma exacerbations; adjusted HRs in NS+AFL-A compared with never-smokers without airflow limitation or asthma (NS-AFL-A) were 7.7 (2.8 to 21) for COPD exacerbations and 1.7 (1.3 to 2.3) for pneumonias. Risk of comorbidities or all-cause mortality was not increased in $\mathrm{NS}+\mathrm{AFL}-\mathrm{A}$ or $\mathrm{NS}+\mathrm{AFL}+\mathrm{A}$ compared with NS-AFL-A.

Conclusions Majority of NS+AFL-A do not seem to have undiagnosed asthma and may instead have airflow limitation caused by other risk factors.

\section{INTRODUCTION}

Tobacco smoking is the single most important risk factor for developing airflow limitation, especially in Western societies. Nevertheless, a substantial proportion of individuals with airflow limitation are neversmokers. ${ }^{1}$ Recently, the prognosis of never-smokers with airflow limitation was unveiled with an increased risk of lung-related hospitalisations. ${ }^{2}$ However, whether never-smokers with airflow

\section{Key messages}

What is the key question?

- Do the majority of symptomatic never-smokers with airflow limitation but without known asthma have undiagnosed asthma.

What is the bottom line?

- The majority of never-smokers with airflow limitation do not seem to have undiagnosed asthma and may instead have airflow limitation caused by other risk factors.

\section{Why read on?}

- This is a large prospective population-based cohort study that investigates the role of asthma as an aetiology of airflow limitation in never-smokers with respiratory symptoms from the general population.

limitation have COPD caused by other risk factors than smoking, or whether they have undiagnosed asthma is unknown. Asthma is an established cause of airflow limitation ${ }^{34}$ and has been associated with an accelerated lung function decline, ${ }^{5-13}$ and increased risk of exacerbations and pneumonias, ${ }^{14}$ independent of smoking status. Furthermore, the prognosis of never-smokers with asthma seems to resemble the prognosis of never-smokers with airflow limitation both with regard to risk of complications and comorbidities. $^{2} 14$ Thus, it would be of clinical importance to investigate whether never-smokers with airflow limitation have undiagnosed asthma.

We hypothesised that the majority of neversmokers with respiratory symptoms and airflow limitation but without known asthma have undiagnosed asthma by comparing characteristics and prognosis in never-smokers with airflow limitation and asthma with never-smokers with airflow limitation but without asthma. For this purpose, we used the Copenhagen General Population Study with 94079 individuals, including 13719 symptomatic never-smokers of whom 1610 had airflow limitation. First, we investigated general and clinical characteristics at baseline. Second, we assessed prospectively risk of complications, including asthma or COPD exacerbations, pneumonias and all-cause mortality, and risk of comorbidities, including lung cancer, ischaemic heart disease, myocardial infarction, deep venous thrombosis and PE. 


\section{METHODS}

\section{Study design and participants}

We recruited 94079 individuals aged 20-100 years from the Copenhagen General Population Study, a prospective population-based cohort study initiated in 2003 with ongoing enrolment. $^{2} 14 \quad 15$ All individuals in Denmark are assigned a unique identification number at birth or immigration and registered in the National Danish Civil Registration System. Thus, participants were randomly selected from the National Danish Civil Registration System to reflect the adult white Danish population of Danish descent. All participants completed a comprehensive questionnaire, underwent a physical examination and gave blood for biochemical analyses. All spirometry measurements were carried out on the day of attendance. Questionnaires were reviewed at the day of attendance by an investigator together with the participant. The study was approved by Herlev and Gentofte Hospital and a Danish ethical committee, and was conducted according to the Declaration of Helsinki. Written informed consent was obtained from all participants.

\section{Classification of the study population according to smoking, asthma and airflow limitation}

Asthma was defined as an affirmative response to the question: "Do you have asthma?" Smoking status was defined as never, former or current smokers; never-smokers were individuals who reported that they had never smoked in their entire life. We subsequently excluded former and current smokers as well as asymptomatic never-smokers to end up with never-smokers reporting to have at least one of the following respiratory symptoms: wheezing, dyspnoea, chest pain or tightness, sputum and cough (figure 1). Additional information about tobacco smoking, including age of onset, duration and daily consumption, was used to ensure that never-smokers were correctly identified.

Spirometry was performed with a Vitalograph (Maids Moreton, Buckinghamshire, UK) in the first 14625 participants and with an EasyOne Spirometer (ndd Medical Technologies, Zurich, Switzerland) in the remaining participants; prebronchodilatatory $\mathrm{FEV}_{1}$ and $\mathrm{FVC}$ were measured with at least three sets of values and had two measurements differing by $<5 \%$ as a criterion for reproducibility. The highest measurements of $\mathrm{FEV}_{1}$ and FVC were used in the analyses. The Vitalograph was calibrated daily with a 1-L syringe, and the EasyOne Spirometer was calibrated regularly as recommended from the manufacturer. $\mathrm{FEV}_{1}, \mathrm{FVC}$ and $\mathrm{FEV}_{1} / \mathrm{FVC}$ as percentage of predicted value were calculated using internally derived reference values based on healthy asymptomatic (without wheezing, dyspnoea, chest pain or tightness, sputum, cough and asthma) never-smokers with age and height as covariates and separately for men and women. Predicted values were calculated separately for the two spirometers, as done previously. ${ }^{14}$ Airflow limitation was defined according to $\mathrm{FEV}_{1} / \mathrm{FVC}<70 \%$. Since the correct definition of airflow limitation is often a subject of dispute, ${ }^{16}$ airflow limitation according to lower limit of normal (LLN) defined as $\mathrm{FEV}_{1} / \mathrm{FVC}<\mathrm{LLN}$, calculated as the mean predicted value for age and sex multiplied by minus $1.645 \mathrm{SE}$, was used in the sensitivity analyses to verify the findings with the fixed ratio.

Classification of symptomatic never-smoking individuals according to asthma and airflow limitation yielded the following four groups:

- Never-smokers without airflow limitation or asthma: neversmoking individuals reporting to have wheezing, dyspnoea, chest pain or tightness, sputum and/or cough with $\mathrm{FEV}_{1}$ $\mathrm{FVC} \geq 70 \%$ and no self-reported asthma.

- Never-smokers with airflow limitation but without asthma: never-smoking individuals reporting to have wheezing, dyspnoea, chest pain or tightness, sputum and/or cough with $\mathrm{FEV}_{1} / \mathrm{FVC}<70 \%$ and no self-reported asthma.

- Never-smokers without airflow limitation but with asthma: never-smoking individuals reporting to have wheezing, dyspnoea, chest pain or tightness, sputum and/or cough with $\mathrm{FEV}_{1} / \mathrm{FVC} \geq 70 \%$ and with self-reported asthma.

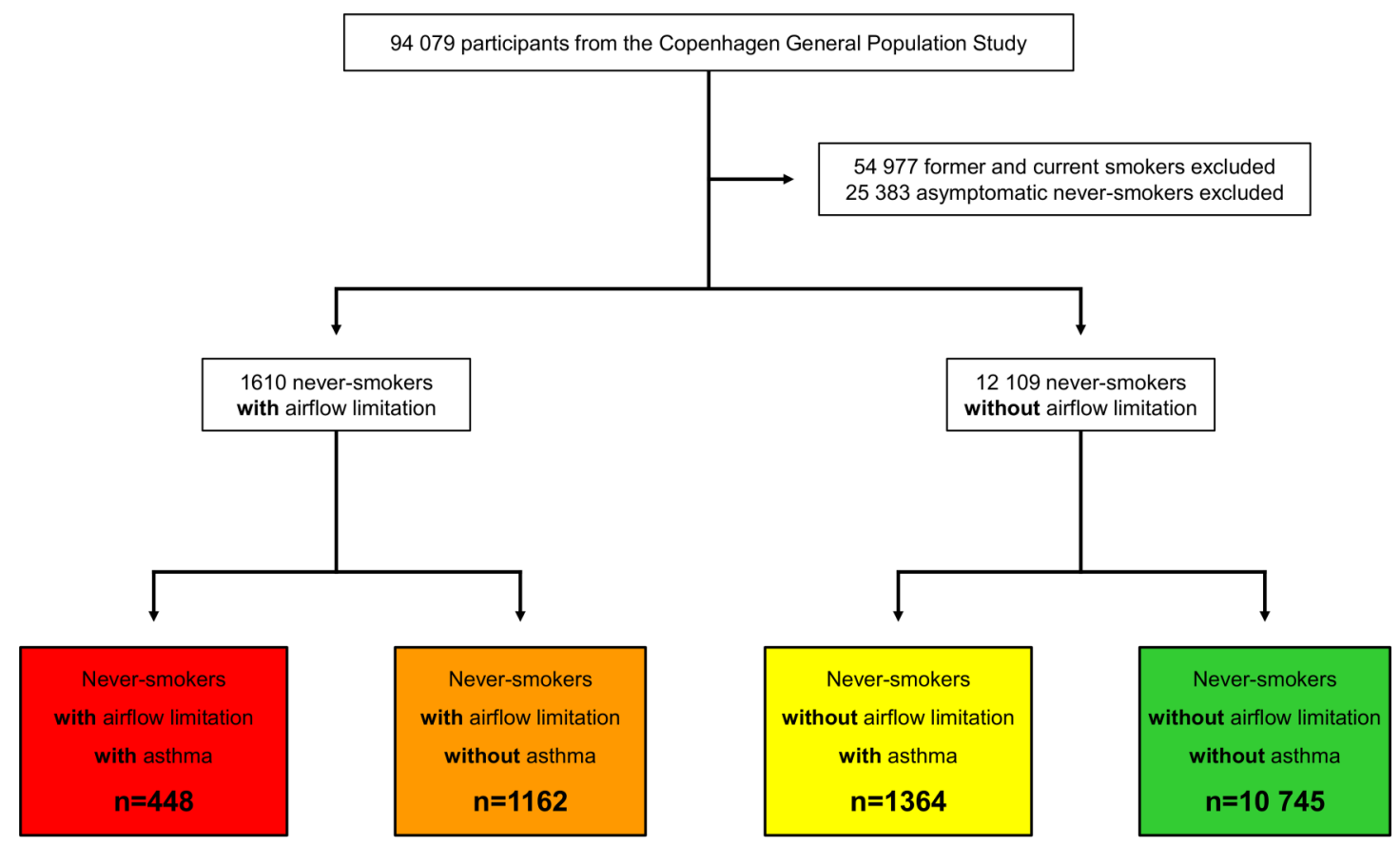

Figure 1 Study population. Airflow limitation was defined according to $\mathrm{FEV}_{1} / \mathrm{FVC}<70 \%$. 
- Never-smokers with airflow limitation and asthma: neversmoking individuals reporting to have wheezing, dyspnoea, chest pain or tightness, sputum and/or cough with $\mathrm{FEV}_{1}$ / FVC $<70 \%$ and with self-reported asthma.

\section{Characteristics}

Allergy was defined according to the questionnaire if the participants reported to have asthma, hay fever or eczema as a reaction to food, medication, grass, flower, animal hair or other allergens. Familial predisposition for asthma was defined as at least one first-degree relative (father, mother and/or sibling) had asthma. Information on asthma, hay fever or eczema in childhood, occupational exposure to dust and/or fumes, and daily exposure to passive smoking was also self-reported. Use of respiratory medication was taking any kind of medication for asthma/bronchitis (including sprays/dry powders) daily or almost

Table 1 General and clinical characteristics of never-smokers according to the presence of airflow limitation and asthma at baseline

\begin{tabular}{|c|c|c|c|c|}
\hline & \multicolumn{2}{|l|}{$\mathrm{FEV}_{1} / \mathrm{FVC}<70 \%$} & \multicolumn{2}{|l|}{$\mathrm{FEV}_{1} / \mathrm{FVC} \geq 70 \%$} \\
\hline & $\begin{array}{l}\text { Asthma } \\
(n=448)\end{array}$ & $\begin{array}{l}\text { No asthma } \\
\text { ( } n=1162)\end{array}$ & $\begin{array}{l}\text { Asthma } \\
(n=1364)\end{array}$ & $\begin{array}{l}\text { No asthma } \\
(n=10745)\end{array}$ \\
\hline \multicolumn{5}{|l|}{ General characteristics } \\
\hline Men (\%) & $43^{*}$ & 31 & $34 \ddagger$ & 33 \\
\hline Age (years) & $64(52-72)^{*}$ & $69(60-78)$ & $51(44-62) \ddagger$ & $58(47-68)$ \\
\hline Weight (kg) & $75(65-85) \dagger$ & $73(64-84)$ & $78(67-88) \S$ & $77(67-89)$ \\
\hline $\mathrm{BMI}\left(\mathrm{kg} / \mathrm{m}^{2}\right)$ & $26(23-28)$ & $26(23-29)$ & $26(24-30) \S$ & $27(24-30)$ \\
\hline $\mathrm{FEV}_{1} \%$ of predicted & $74(61-85)^{*}$ & 83 (71-93) & $93(85-102) \ddagger$ & $96(87-106)$ \\
\hline FVC $\%$ of predicted & $90(78-102)^{*}$ & $98(85-108)$ & $94(86-103) \ddagger$ & $95(86-104)$ \\
\hline $\mathrm{FEV}_{1} / \mathrm{FVC}(\%)$ & $64(59-67)^{*}$ & $66(62-68)$ & $79(75-82) \ddagger$ & $80(76-83)$ \\
\hline Familial predisposition for asthma (\%) & $36^{*}$ & 20 & $43 \S$ & 19 \\
\hline Asthma, hay fever, or eczema in childhood (\%) & $51^{*}$ & 12 & 48 & 15 \\
\hline Low leisure time physical activity (\%) & 7 & 9 & 8 & 9 \\
\hline Low education (\%) & $26 t$ & 33 & $18 \ddagger$ & 26 \\
\hline Low annual household income (\%) & $17 \dagger$ & 23 & $11 \S$ & 15 \\
\hline Occupational exposure to dust and/or fumes (\%) & $12 \dagger$ & 8 & 13 & 10 \\
\hline Daily exposure to passive smoking (\%) & 14 & 14 & $23 \ddagger$ & 21 \\
\hline \multicolumn{5}{|l|}{ Clinical characteristics } \\
\hline Allergy (\%) & $83^{*}$ & 29 & 85 & 33 \\
\hline Use of respiratory medication (\%) & $79^{*}$ & 5 & $65 \ddagger$ & 2 \\
\hline Duration of asthma (years) & $28(12-43)$ & $N A$ & $18(8-30) \ddagger$ & $N A$ \\
\hline \multicolumn{5}{|l|}{ Respiratory symptoms } \\
\hline Wheezing (\%) & $79^{*}$ & 27 & 76 & 25 \\
\hline During a cold (\%) & 53 & 60 & 58 & 65 \\
\hline During activity (\%) & $55^{*}$ & 31 & 54 & 24 \\
\hline Unknown situations (\%) & $21+$ & 32 & 22 & 30 \\
\hline Dyspnoeaๆ (\%) & $68^{*}$ & 79 & $60 \S$ & 77 \\
\hline Nighttime dyspnoea (\%) & $21^{*}$ & 7 & 19 & 7 \\
\hline$m M R C \geq 2(\%)$ & 22 & 22 & $16 \S$ & 16 \\
\hline Chest pain or tightness (\%) & 10 & 10 & 7 & 8 \\
\hline Sputum (\%) & $24 t$ & 17 & $19 \S$ & 13 \\
\hline Cough (\%) & $41^{*}$ & 21 & $50 \S$ & 22 \\
\hline Any respiratory symptoms (\%) & 100 & 100 & 100 & 100 \\
\hline \multicolumn{5}{|l|}{ Severity of airflow limitation } \\
\hline $\mathrm{FEV}_{1} \%$ of predicted $\geq 80(\%)$ & $36^{*}$ & 58 & $85 \ddagger$ & 89 \\
\hline$\geq 60 \mathrm{FEV}_{1} \%$ of predicted $<80(\%)$ & $40+$ & 32 & $14 \ddagger$ & 10 \\
\hline $\mathrm{FEV}_{1} \%$ of predicted $<60(\%)$ & $24^{*}$ & 10 & $1 \ddagger$ & 1 \\
\hline \multicolumn{5}{|c|}{ Level of inflammatory biomarkers in the systemic circulation } \\
\hline $\mathrm{C}$ reactive protein $(\mathrm{mg} / \mathrm{L})$ & $1.5(1.0-2.3)$ & $1.5(1.0-2.6)$ & $1.5(1.0-2.6)$ & $1.5(1.0-2.6)$ \\
\hline Fibrinogen $(\mu \mathrm{mol} / \mathrm{L})$ & $10.9(9.4-13.0)$ & $11.1(9.8-12.9)$ & $10.6(9.3-12.5)$ & $11.0(9.5-12.7)$ \\
\hline Leucocytes $\left(\times 10^{9} / \mathrm{L}\right)$ & $7.2(6.2-8.4)^{*}$ & $6.9(5.9-8.0)$ & $7.1(6.2-8.1)$ & $6.9(6.0-8.1)$ \\
\hline Neutrophils $\left(\times 10^{9} / \mathrm{L}\right)$ & $4.2(3.4-5.2) \dagger$ & $4.0(3.3-4.9)$ & $4.1(3.4-4.9) \S$ & $4.0(3.3-4.9)$ \\
\hline Eosinophils $\left(\times 10^{9} / \mathrm{L}\right)$ & $0.27(0.17-0.40)^{*}$ & $0.17(0.11-0.25)$ & $0.21(0.13-0.33) \ddagger$ & $0.16(0.11-0.24)$ \\
\hline $\lg \mathrm{E}^{* *}(\mathrm{IU} / \mathrm{mL})$ & $77(29-188)^{*}$ & $26(9-61)$ & $48(20-104) \ddagger$ & $23(8-52)$ \\
\hline
\end{tabular}

Data are summarised as median with the 25 th and 75 th percentiles, or per cent.

${ }^{*} \mathrm{p}<0.001$ and $\mathrm{t} p<0.05$ for comparison among individuals with airflow limitation, calculated using Pearson's $\chi^{2}$ test if comparing categorical data and Wilcoxon's non-parametric rank-sum test if comparing continues data.

$\neq p<0.001$ and $\$ p<0.05$ for comparison among individuals with asthma, calculated using Pearson's $\chi^{2}$ test if comparing categorical data and Wilcoxon's non-parametric rank-sum test if comparing continues data.

IDyspnoea was shortness of breath during different levels of activity, at nighttime, and/or while seated/at rest.

** Not available for all individuals listed in the table.

BMI, body mass index; mMRC, modified Medical Research Council dyspnoea scale; NA, not applicable. 
daily. Wheezing was whistling or wheezing while breathing. Dyspnoea was defined as shortness of breath during different levels of activity, at nighttime and/or while seated/at rest. A modified Medical Research Council dyspnoea scale was used to categorise levels of dyspnoea according to different levels of activity. Chest pain or tightness was when hurrying or taking the stairs. Sputum was phlegm from the lungs in the morning and/or during the day as long as three consecutive months each year. Cough was exercise induced cough. Severity of airflow limitation was assessed using $\mathrm{FEV}_{1}$ as percentage of predicted value and categorised into $<60 \%, 60-79 \%$ and $\geq 80 \%$. Inflammatory biomarkers in the systemic circulation, including C reactive protein, fibrinogen, whole blood leucocyte count, whole blood neutrophils, whole blood eosinophils and IgE were measured using standard hospital assays; measurement of IgE was only available in a subgroup of 38962 participants.

\section{Complications and comorbidities}

Information on asthma exacerbations (ICD8:493 and ICD10: J45-J46), COPD exacerbations (ICD8:491-492 and ICD10: J41-J44), pneumonias (ICD8:480-486 and ICD10:J12-J18), ischaemic heart disease (ICD8:410-414 and ICD10:I20-I25), myocardial infarction (ICD8:410 and ICD10:I21-I22), deep venous thrombosis (ICD8:451.00, 451.08-09, 451.90, 451.92, 671.01-03, 671.08-09 and ICD10:I80.1-3, O22.3, O87.1), and PE (ICD8:450.99, 673.99 and ICD10:I26.0, I26.9, O88.2) was obtained from the National Danish Patient Registry, recorded from 1977 until April 2013, which covers all public and private Danish hospitals (including emergency departments and outpatients since 1995), and from the National Causes of Death Registry, recorded from 1977 until April 2013. Exacerbations and pneumonias were defined as emergency department visits or hospital admissions with the primary discharged diagnosis, or on death certificates made by a doctor according to the national law. Ischaemic heart disease, myocardial infarction, deep venous thrombosis and PE were defined as inpatient and outpatient hospital contacts with the primary and secondary discharged diagnosis, or on death certificates made by a doctor according to the national law. Information on lung cancer (ICD10:C34) was obtained from the National Danish Cancer Registry, recorded until December 2011 reported by a doctor according to the national law. Information on all-cause
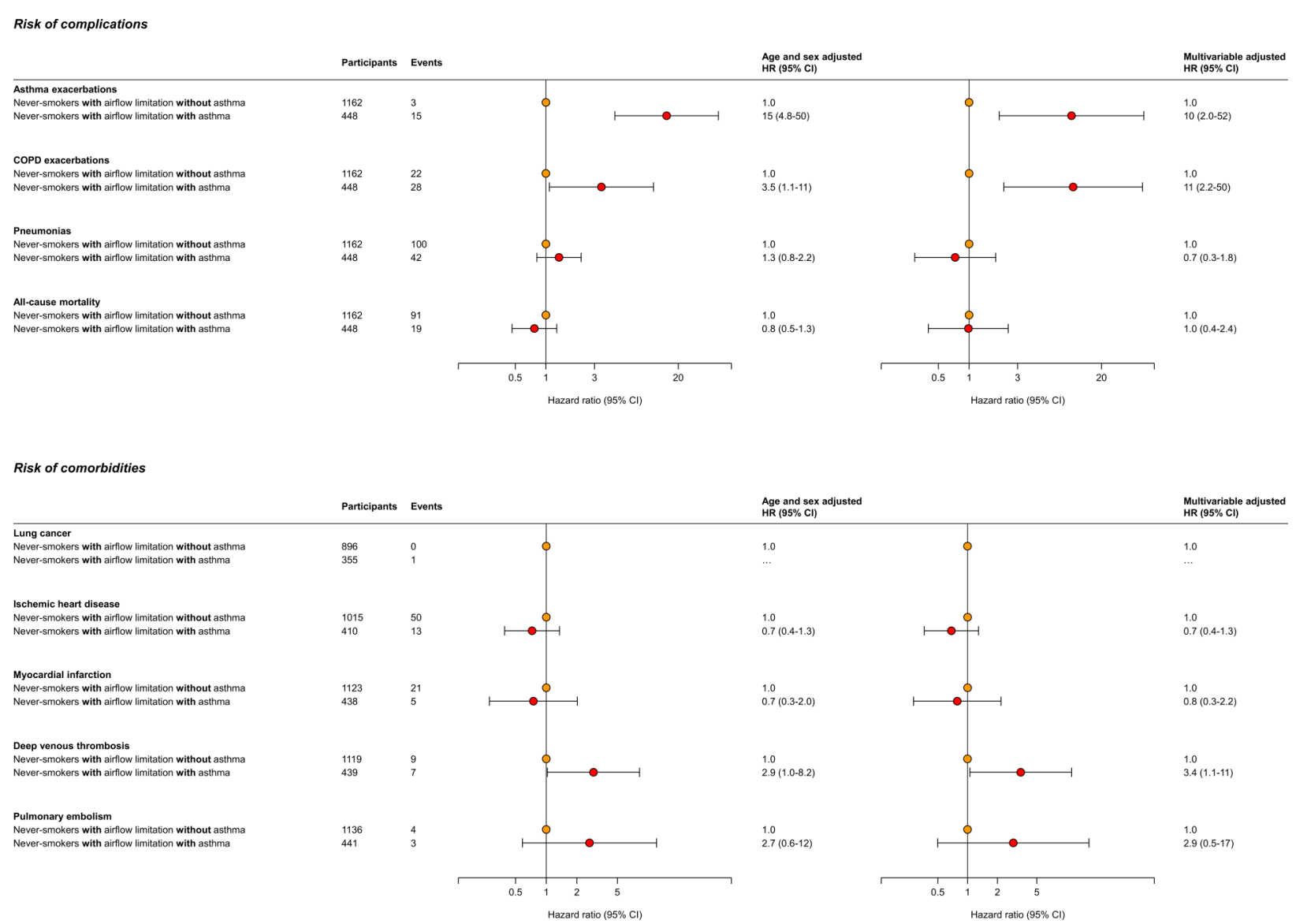

Figure 2 Risk of complications and comorbidities according to the presence and absence of asthma in never-smokers with airflow limitation. Airflow limitation was defined according to $\mathrm{FEV}_{1} / \mathrm{FVC}<70 \%$. Models on risk of exacerbations and pneumonias were multivariable adjusted for age, sex, body mass index, familial predisposition for asthma, allergy, childhood asthma, hay fever or eczema, use of respiratory medication, occupational exposure to dust and/or fumes, daily exposure to passive smoking, leisure time physical activity, education and annual household income. Models on risk of ischaemic heart disease, myocardial infarction, deep venous thrombosis and PE were multivariable adjusted for age, sex, body mass index, leisure time physical activity, education, annual household income, alcohol consumption, systolic and diastolic blood pressure, low-density lipoprotein cholesterol, high-density lipoprotein cholesterol, triglycerides, use of cholesterol-lowering medication and presence of diabetes. Model on risk of all-cause mortality was multivariable adjusted for all of the above-mentioned potential confounders. Number of individuals for lung cancer differs slightly due to availability of data. Numbers of individuals for the other comorbidities differ slightly due to exclusion of participants with the outcome at baseline. 
mortality was obtained from the National Danish Civil Registration System, recorded until April 2013 reported by a doctor according to the national law.

Since all individuals in Denmark have a unique identification number in the National Danish Civil Registration System, they can be tracked in the registries described above. Thus, not a single person was lost to follow-up, and the individuals who emigrated from Denmark were censored at the date of emigration. The National Danish Patient Registry and Danish Cancer Registry have high validity of recorded data. ${ }^{17} 18$

\section{Covariates}

Systolic and diastolic blood pressures were measured using automated equipment. Plasma levels of total cholesterol, low-density lipoprotein (LDL) cholesterol, high-density lipoprotein (HDL) cholesterol and triglycerides were measured using standard hospital assays. Diabetes at baseline was (1) self-reported diabetes, (2) non-fasting plasma glucose $>11 \mathrm{mmol} / \mathrm{L}$, (3) use of antidiabetic medication and/or (4) inpatient and outpatient hospital contacts with type-1 diabetes (ICD8:249 and ICD10:E10) and/or type-2 diabetes or unspecified diabetes (ICD8:250 and ICD10: E11, E13, E14) derived from the National Danish Patient Registry or Danish Causes of Death Registry reported by a doctor according to the national law. Body mass index (BMI) was calculated as measured weight divided by measured height squared $\left(\mathrm{kg} / \mathrm{m}^{2}\right)$. Information on the use of cholesterol-lowering medication, leisure time physical activity, education, annual household income and alcohol consumption was derived from the questionnaire.

\section{Statistical analyses}

For comparison, Wilcoxon's non-parametric rank-sum test was used for continuous data and Pearsons $\chi^{2}$ test for categorical data. Multivariable adjusted Cox proportional HRs with 95\% CIs were used in the prospective analyses, determining risk of complications and comorbidities. For exacerbations and pneumonias, we carried out multiple failure-time analysis using the Andersen-Gill approach, ${ }^{19}$ meaning that individuals were at risk of recurrent events. Otherwise, an approach with single failuretime analysis was used. When investigating the prognosis among the subgroups with airflow limitation, those without asthma were used as the reference group. However, in the analyses comprising the whole study population, those without airflow limitation or asthma were the reference group. The Wald test was used to assess possible interaction of airflow limitation and asthma on risk of complications and comorbidities. Models on risk of exacerbations, pneumonias and lung cancer were adjusted for potential confounders associated with one or more of these diseases, that is, for age, sex, BMI, allergy, familial predisposition for asthma, childhood asthma, hay fever or eczema, use of respiratory medication, occupational exposure to dust and/or fumes, daily exposure to passive smoking, leisure time physical activity, education and annual household income. Models on risk of ischaemic heart disease, myocardial infarction, deep venous thrombosis and PE were adjusted for potential confounders associated with one or more of these diseases, that is, for age, sex, BMI, leisure time physical activity, education, annual household income, alcohol consumption, systolic and diastolic blood pressure, LDL cholesterol, HDL cholesterol, triglycerides, use of cholesterol-lowering medication and presence of diabetes. Model on risk of all-cause mortality was adjusted for all of the above-mentioned potential confounders, as all of them may be relevant with regard to this endpoint. Multivariable adjusted logistic regression models were used to identify risk factors for airflow limitation in never-smokers with and without asthma. Potential risk factors for airflow limitation

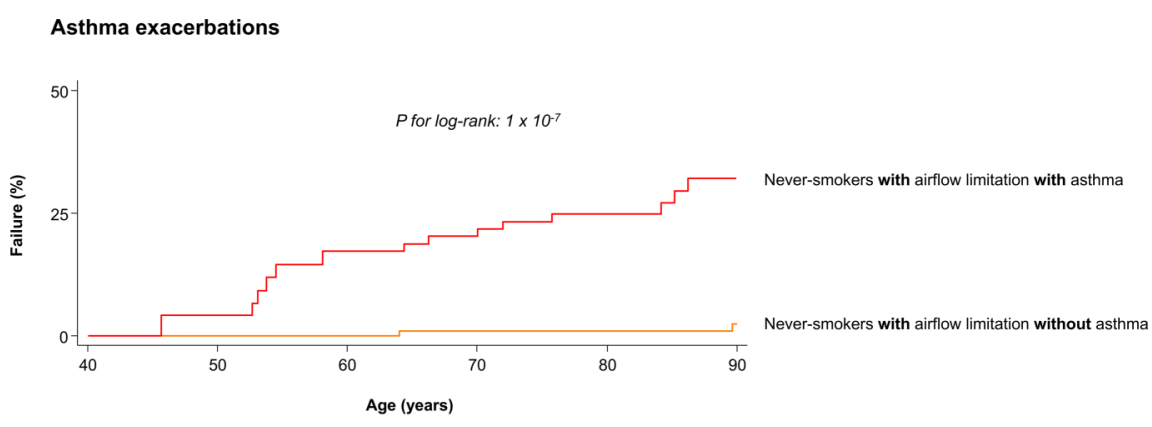

COPD exacerbations

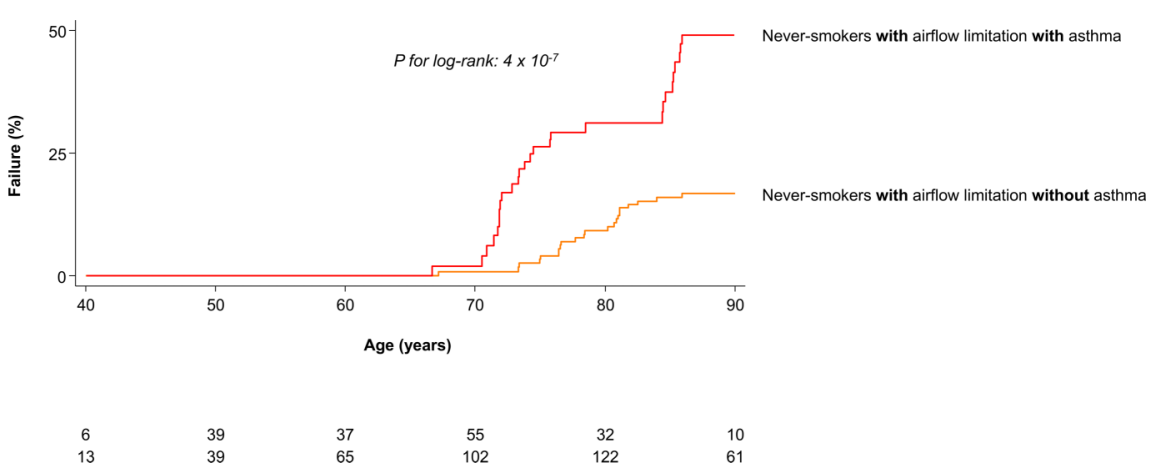
Never-smokers with airflow limitation with asthma $13 \quad 39$

102

122

61

Figure 3 Kaplan-Meier failure curves according to the presence and absence of asthma in never-smokers with airflow limitation. Since age is used as timescale and individuals entered the study at different ages, numbers of individuals at risk in each age group are lower than the total numbers given in figure 2; however, all individuals in figure 2 were entered into this analysis. 
that were included in the models were dichotomous except BMI, duration of asthma and inflammatory biomarkers that were continuous.

Covariates used for adjustment in the prospective analyses were $99.2 \%$ complete. Therefore, we performed multivariate imputation using chained equations to fill out the missing values ${ }^{20}$ however, results were similar without the use of imputation.

All statistical analyses were performed using STATA/SE V.13.0 for Windows (StataCorp, College Station, Texas, USA).

\section{RESULTS}

Among 94079 participants in the Copenhagen General Population Study, 39102 (42\%) were never-smokers. In this group, 13719 (35\%) reported having wheezing, dyspnoea, chest pain or tightness, sputum and/or cough, of whom 1610 (12\%) had airflow limitation (figure 1). The prevalence of asthma was $28 \%$ among never-smokers with airflow limitation, and $11 \%$ among never-smokers without airflow limitation. Median follow-up was approximately 4.5 years (ranging from 1 day to 9.4 years).

\section{Characteristics}

Never-smokers with airflow limitation but without asthma compared with never-smokers with airflow limitation and asthma had a lower prevalence of familial predisposition for asthma, allergy, and of asthma, hay fever or eczema during childhood (table 1). Never-smokers with airflow limitation but without asthma generally also had a lower prevalence of respiratory symptoms, higher $\mathrm{FEV}_{1}$ as percentage of predicted value and a markedly lower use of respiratory medication (5\% vs $79 \%$ ). Blood analyses showed that this group also had lower levels of inflammatory biomarkers, especially eosinophils and IgE.

\section{Complications and comorbidities}

Never-smokers with airflow limitation and asthma compared with never-smokers with airflow limitation but without asthma had an increased risk of asthma and COPD exacerbations (figures 2 and 3): multivariable adjusted HRs in never-smokers with airflow limitation with versus without asthma were 10 (95\% CI 2.0 to 52) for asthma exacerbations and 11 (2.2 to 50) for COPD exacerbations. In contrast, risk of pneumonias, comorbidities and all-cause mortality was not increased (figure 2). Risk of comorbidities did not differ among these two groups; however, never-smokers with airflow limitation and asthma had an increased risk of deep venous thrombosis: multivariable adjusted HR 3.4 (1.1 to 11). Increasing severity of airflow limitation in never-smokers with airflow limitation but without asthma was associated with an increased risk of pneumonias and all-cause mortality but did not reach statistical significance for never-smokers with airflow limitation and asthma (figure 4). Furthermore, risk of other complications and comorbidities by increasing severity of airflow limitation did also not reach statistical significance in both never-smokers with and without asthma.

In the whole population of never-smokers and compared with never-smokers without airflow limitation or asthma, neversmokers with airflow limitation but without asthma had an
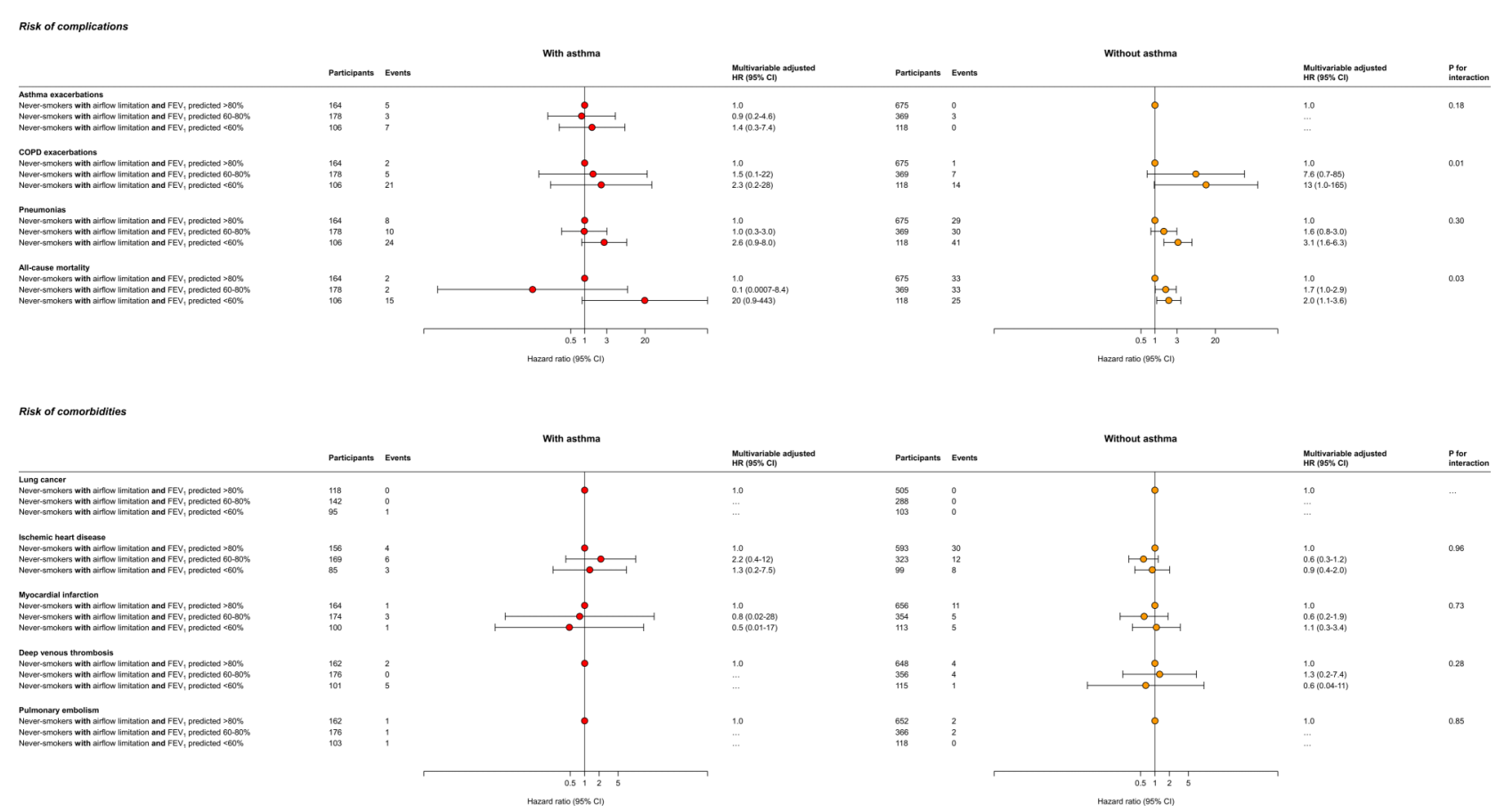

Figure 4 Risk of complications and comorbidities according to severity of airflow limitation and presence and absence of asthma in never-smokers with airflow limitation. Airflow limitation was defined according to $\mathrm{FEV}_{1} / \mathrm{FVC}<70 \%$. Models on risk of exacerbations and pneumonias were multivariable adjusted for age, sex, body mass index, familial predisposition for asthma, allergy, childhood asthma, hay fever, or eczema, use of respiratory medication, occupational exposure to dust and/or fumes, daily exposure to passive smoking, leisure time physical activity, education and annual household income. Models on risk of ischaemic heart disease, myocardial infarction, deep venous thrombosis and PE were multivariable adjusted for age, sex, body mass index, leisure time physical activity, education, annual household income, alcohol consumption, systolic and diastolic blood pressure, low-density lipoprotein cholesterol, high-density lipoprotein cholesterol, triglycerides, use of cholesterol-lowering medication and presence of diabetes. Model on risk of all-cause mortality was multivariable adjusted for all of the above-mentioned potential confounders. $P$ for interaction of $\mathrm{FEV}_{1} \%$ of predicted and asthma was assessed using the Wald test. Number of individuals for lung cancer differs slightly due to availability of data. Numbers of individuals for the other comorbidities differ slightly due to exclusion of participants with the outcome at baseline. 
increased risk of COPD exacerbations and pneumonias, but not of asthma exacerbations or all-cause mortality (figure 5). By contrast, never-smokers with airflow limitation and asthma had an increased risk of both asthma and COPD exacerbations, but not of pneumonias or all-cause mortality. Risk of other comorbidities did not differ among all four groups, including never-smokers with airflow limitation and asthma (figure 6).

\section{Sensitivity analyses}

When using the LLN criterion, the prevalence of airflow limitation changed from $10 \%$ to $6 \%$ in individuals without asthma and from $25 \%$ to $22 \%$ in individuals with asthma (see supplementary figure S1 in the Online Data Repository). When using the LLN criterion, findings were similar both with regard to risk of complications and comorbidities in never-smokers with airflow limitation (compare figure 2 with online supplementary figure S2); however, never-smokers with airflow limitation and asthma were no longer at risk of deep venous thromboembolism. Additionally, when using the LLN criterion, findings were similar both with regard to risk of complications and comorbidities by increasing severity of airflow limitation in never-smokers with and without asthma (compare figure 4 with online supplementary figure S3); however, it did not reach statistical significance in never-smokers with airflow limitation but without asthma with regard to risk of all-cause mortality. Findings were also similar in the whole population of neversmokers (compare figures 5 and 6 with online supplementary figures S4 and S5).

\section{Risk factors for airflow limitation in never-smokers with and without asthma}

In never-smokers with asthma, higher levels of neutrophils and eosinophils and a longer duration of asthma were associated with a higher risk of airflow limitation (table 2). In neversmokers without asthma, low physical inactivity, familial predisposition for asthma and higher levels of eosinophils were associated with a higher risk of airflow limitation. When using the LLN criterion, findings were similar for both never-smokers with and without asthma (compare table 2 with online supplementary table S1); however, low income was now associated with higher risk of airflow limitation in never-smokers without asthma.

\section{DISCUSSION}

In this large sample of the general population, approximately $12 \%$ of symptomatic never-smoking individuals had airflow limitation of whom only $28 \%$ reported to have the diagnosis of asthma. Never-smokers with airflow limitation but without asthma compared with never-smokers with airflow limitation and asthma differed with regard to several characteristics, including respiratory symptoms, $\mathrm{FEV}_{1}$, and levels of eosinophils and IgE. Additionally, never-smokers with airflow limitation and asthma compared with never-smokers with airflow limitation but without asthma had an increased risk of asthma and COPD exacerbations, but not of pneumonias. Still, never-smokers with airflow limitation but without asthma had an increased risk of COPD exacerbations and pneumonias, but not of asthma exacerbations compared with never-smokers without airflow limitation or asthma. Furthermore, the presence of asthma or airflow limitation in never-smokers did not seem to increase the risk of all-cause mortality or comorbidities.

Some individuals with asthma will develop a chronic condition, characterised by persistent airflow limitation that is not readily reversible with bronchodilators. ${ }^{21}$ Furthermore, the presence of airflow limitation in never-smokers with asthma is a sign of a more severe disease. ${ }^{22}{ }^{23}$ Since chronic asthma is difficult to differentiate from COPD, ${ }^{24}$ it was not surprising to observe an increased risk of COPD exacerbations in individuals with asthma and airflow limitation. Accelerated lung function decline combined with increasing age is the most probable mechanism for developing persistent airflow limitation in asthma. ${ }^{5-13}$ Supportive of this notion is that among individuals with asthma, those with airflow limitation compared with those without had a longer duration of asthma and a higher age.

The intriguing question is whether never-smokers with airflow limitation but without known asthma have undiagnosed

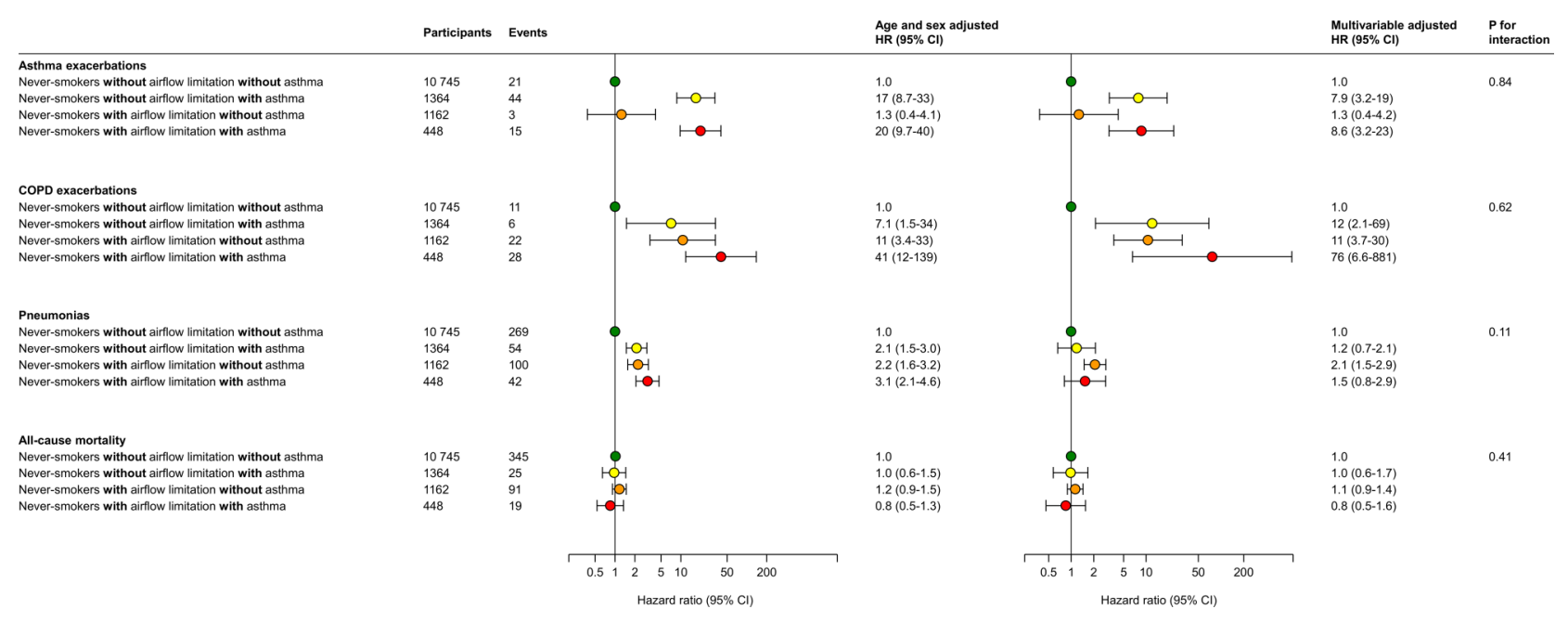

Figure 5 Risk of complications according to the presence of airflow limitation and asthma in never-smokers. Airflow limitation was defined according to $\mathrm{FEV}_{1} / \mathrm{FVC}<70 \%$. Models on risk of exacerbations and pneumonias were multivariable adjusted for age, sex, body mass index, familial predisposition for asthma, allergy, childhood asthma, hay fever or eczema, use of respiratory medication, occupational exposure to dust and/or fumes, daily exposure to passive smoking, leisure time physical activity, education and annual household income. Model on risk of all-cause mortality was additionally multivariable adjusted for alcohol consumption, systolic and diastolic blood pressure, low-density lipoprotein cholesterol, high-density lipoprotein cholesterol, triglycerides, use of cholesterol-lowering medication and the presence of diabetes. $p$ for interaction of airflow limitation and asthma was assessed using the Wald test. 
asthma. Never-smokers with airflow limitation have previously been shown to have milder disease with a better prognosis compared with smokers with COPD, and they were suggested to have COPD caused by other risk factors than smoking. ${ }^{25-30}$ However, in a previous analysis of our cohort, these individuals did not differ substantially from never-smokers without airflow limitation with regard to the well-known risk factors for COPD, including occupational exposure, exposure to passive smoking, socioeconomic status and levels of $\alpha 1$-antitrypsin. ${ }^{2}$ Furthermore, it also seems that the prognosis of never-smokers with asthma resembles the prognosis of never-smokers with airflow limitation. ${ }^{214}$ Yet, we found that the well-known clinical characteristics of asthma, including allergy, wheezing, familial predisposition for asthma and increased levels of eosinophils and $\mathrm{IgE}^{22}$ were more prevalent in individuals reporting to have asthma as opposed to those who did not.

Approximately, $72 \%$ of never-smoking individuals with airflow limitation did not report to have asthma. These individuals had an increased risk of COPD exacerbations and pneumonias, but not of asthma exacerbations. Thus, it would be reasonable to assume that most of them have COPD caused by other risk factors than smoking. However, although they were symptomatic and the spirometric criterion for airflow limitation was fulfilled, they did not differ substantially compared with never-smokers without airflow limitation or asthma both with regard to relevant exposures and clinical characteristics, including in the use of respiratory medication, presence of respiratory symptoms and levels of inflammatory biomarkers in blood. Thus, it is disputable whether they qualify for the clinical diagnosis of COPD. ${ }^{24}$ Airflow limitation in these individuals could be caused by other factors affecting lung growth and resulting in a lower lung function already in early adulthood. ${ }^{31}$
Development of airflow limitation will become imminent when combining the disadvantageous lower lung function in early adulthood and a normal or only slightly increased age-related decline of $\mathrm{FEV}_{1}{ }^{31-35}$ Interestingly, it has been suggested that airflow limitation in never-smokers includes at least two pathologic subgroups; ${ }^{36}$ one characterised by high levels of eosinophils associated with airway remodelling secondary to asthma and another characterised by high levels of neutrophils associated with organ-specific autoimmune disease. Among the inflammatory biomarkers, we were able to identify higher levels of eosinophils as a possible risk factor for airflow limitation in individuals without asthma, whereas higher levels of eosinophils and neutrophils were identified as a possible risk factor for airflow limitation in individuals with asthma.

Strengths of the present study include a large sample of neversmoking individuals randomly selected from the general population with a substantial number of individuals with asthma, and the fact that we did not lose track of even a single person during follow-up. We also had information on several clinical attributes and potential confounders as well as on many important endpoints. Furthermore, as we only included individuals with respiratory symptoms in our analyses, we believe that these participants do not represent the lower end of a normal distribution, but individuals with a clinical problem.

A limitation of our study includes the diagnosis of asthma, which was self-reported and not defined according to the presence of reversible or variable airflow limitation and/or airway hyperresponsiveness. ${ }^{22}$ However, self-reported asthma has been evaluated rigorously before and displays high specificity and sensitivity in epidemiological settings ${ }^{37}$ compared with airway hyperresponsiveness, which only displays high specificity and low sensitivity. ${ }^{38}$ Importantly, lack of postbronchodilatatory

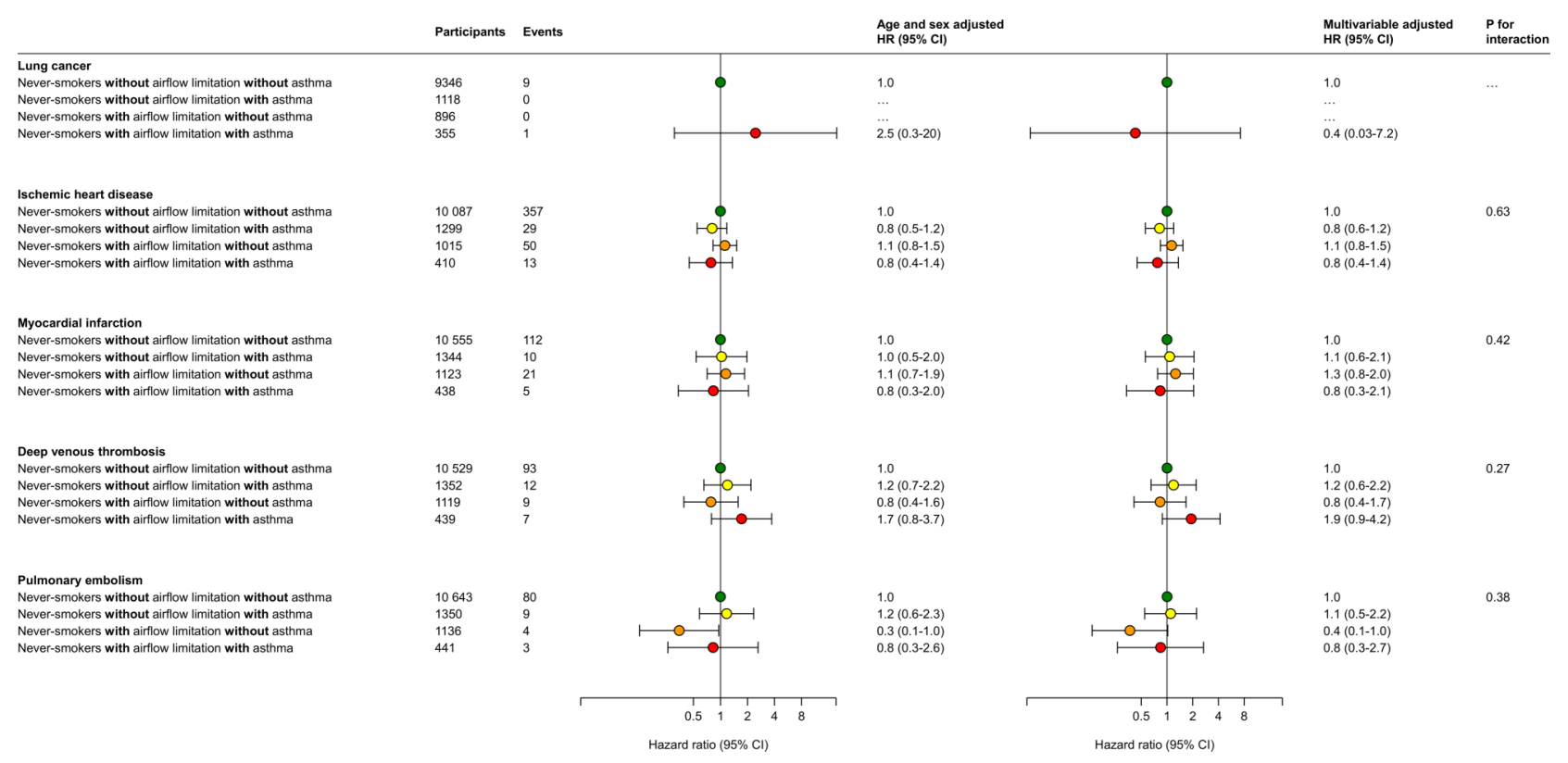

Figure 6 Risk of comorbidities according to the presence of airflow limitation and asthma in never-smokers. Airflow limitation was defined according to $\mathrm{FEV}_{1} / \mathrm{FVC}<70 \%$. Model on risk of lung cancer was multivariable adjusted for age, sex, body mass index, familial predisposition for asthma, allergy, childhood asthma, hay fever or eczema, use of respiratory medication, occupational exposure to dust and/or fumes, daily exposure to passive smoking, leisure time physical activity, education and annual household income. Models on risk of ischaemic heart disease, myocardial infarction, deep venous thrombosis and PE were multivariable adjusted for age, sex, body mass index, leisure time physical activity, education, annual household income, alcohol consumption, systolic and diastolic blood pressure, low-density lipoprotein cholesterol, high-density lipoprotein cholesterol, triglycerides, use of cholesterol-lowering medication and presence of diabetes. $p$ for interaction of airflow limitation and asthma was assessed using the Wald test. Number of individuals for lung cancer differs slightly due to availability of data. Numbers of individuals for the other comorbidities differ slightly due to exclusion of participants with the outcome at baseline. 
Table 2 Risk factors for airflow limitation defined as $\mathrm{FEV}_{1} / \mathrm{FVC}<70 \%$ in never-smokers with and without asthma

\begin{tabular}{|c|c|c|c|c|}
\hline & \multicolumn{2}{|l|}{$\begin{array}{l}\text { Never-smokers with asthma } \\
(n=2304)\end{array}$} & \multicolumn{2}{|c|}{$\begin{array}{l}\text { Never-smokers without asthma } \\
(\mathrm{n}=36 \mathrm{698})\end{array}$} \\
\hline & $\begin{array}{l}\text { Age and sex-adjusted ORs } \\
(95 \% \mathrm{Cl})\end{array}$ & $\begin{array}{l}\text { Multivariable-adjusted ORs } \\
(95 \% \mathrm{Cl})\end{array}$ & $\begin{array}{l}\text { Age and sex-adjusted ORs } \\
(95 \% \mathrm{Cl})\end{array}$ & $\begin{array}{l}\text { Multivariable-adjusted ORs } \\
(95 \% \mathrm{CI})\end{array}$ \\
\hline \multicolumn{5}{|l|}{ Risk factors } \\
\hline BMI $\left(\mathrm{kg} / \mathrm{m}^{2}\right)$ & $0.94(0.91 \text { to } 0.96)^{*}$ & $0.94(0.92 \text { to } 0.97)^{*}$ & $0.95(0.94 \text { to } 0.96)^{*}$ & $0.95(0.94 \text { to } 0.96)^{*}$ \\
\hline $\begin{array}{l}\text { Familial predisposition for } \\
\text { asthma }\end{array}$ & 0.97 (0.78 to 1.21$)$ & 0.98 (0.79 to 1.23 ) & $1.26(1.13 \text { to } 1.40)^{*}$ & $1.29(1.17 \text { to } 1.44)^{*}$ \\
\hline $\begin{array}{l}\text { Asthma, hay fever, or eczema in } \\
\text { childhood }\end{array}$ & $1.49(1.20 \text { to } 1.85)^{*}$ & 0.99 (0.76 to 1.29$)$ & $1.18(1.05$ to 1.34$) \dagger$ & $1.13(0.99$ to 1.29$)$ \\
\hline $\begin{array}{l}\text { Low leisure time physical } \\
\text { activity } \ddagger\end{array}$ & 0.95 (0.62 to 1.46$)$ & 1.05 (0.67 to 1.64$)$ & 1.21 (1.03 to 1.44$) \dagger$ & $1.44(1.21 \text { to } 1.71)^{*}$ \\
\hline Low education§ & $0.76(0.58$ to 0.99$) \dagger$ & 1.00 (0.74 to 1.34 ) & $0.77(0.70 \text { to } 0.84)^{*}$ & $0.83(0.75 \text { to } 0.91)^{*}$ \\
\hline Low annual household incomeq & 0.79 (0.57 to 1.10$)$ & 0.89 (0.62 to 1.27$)$ & 0.94 (0.84 to 1.05$)$ & $1.07(0.95$ to 1.20$)$ \\
\hline $\begin{array}{l}\text { Occupational exposure to dust } \\
\text { and/or fumes }\end{array}$ & 0.82 (0.59 to 1.14$)$ & $0.95(0.67$ to 1.35$)$ & $0.86(0.73$ to 1.00$)$ & $1.00(0.85$ to 1.18$)$ \\
\hline $\begin{array}{l}\text { Daily exposure to passive } \\
\text { smoking }\end{array}$ & $0.71(0.53$ to 0.94$) \dagger$ & 0.77 (0.57 to 1.04 ) & $0.76(0.68 \text { to } 0.86)^{*}$ & $0.82(0.73 \text { to } 0.93)^{*}$ \\
\hline Allergy & 1.16 (0.88 to 1.53$)$ & 0.93 (0.69 to 1.25$)$ & 1.05 (0.96 to 1.15$)$ & $0.99(0.90$ to 1.09$)$ \\
\hline Duration of asthma (years) & $1.02(1.02 \text { to } 1.03)^{*}$ & $1.02(1.01 \text { to } 1.03)^{*}$ & $N A$ & $N A$ \\
\hline $\mathrm{C}$ reactive protein $(\mathrm{mg} / \mathrm{L})$ & 1.00 (0.98 to 1.02 ) & 1.00 (0.98 to 1.03 ) & 1.00 (0.99 to 1.00$)$ & 1.01 (1.00 to 1.02 ) \\
\hline Fibrinogen $(\mu \mathrm{mol} / \mathrm{L})$ & 0.97 (0.93 to 1.01$)$ & 0.98 (0.93 to 1.03 ) & $0.95(0.94 \text { to } 0.97)^{*}$ & $0.97(0.95 \text { to } 0.98)^{*}$ \\
\hline Leucocytes $\left(\times 10^{9} / \mathrm{L}\right)$ & 1.03 (0.98 to 1.09$)$ & 0.88 (0.76 to 1.03 ) & $0.98(0.95$ to 1.00$) \dagger$ & 0.98 (0.94 to 1.01$)$ \\
\hline Neutrophils $\left(\times 10^{9} / \mathrm{L}\right)$ & 1.05 (0.98 to 1.13$)$ & $1.25(1.04$ to 1.50$) \dagger$ & 0.98 (0.96 to 1.01$)$ & 1.02 (0.98 to 1.08$)$ \\
\hline Eosinophils $\left(0.10 \times 10^{9} / \mathrm{L}\right)$ & $1.14(1.08 \text { to } 1.20)^{*}$ & $1.16(1.09 \text { to } 1.23)^{*}$ & $1.03(1.00$ to 1.05$) \dagger$ & $1.04(1.01$ to 1.07$) \dagger$ \\
\hline $\lg E^{* *}(10 \mathrm{IU} / \mathrm{mL})$ & 1.00 (1.00 to 1.00$)$ & 1.00 (1.00 to 1.00$)$ & 1.00 (1.00 to 1.00$)$ & 1.00 (1.00 to 1.00$)$ \\
\hline
\end{tabular}

spirometric values may lead to misclassification. Thus, among never-smokers with airflow limitation, some may have reversible airflow limitation indicating asthma and some may have irreversible airflow limitation indicating COPD or asthma-COPD overlap. Although postbronchodilatatory spirometric values were not available, it was very clear that among never-smokers with airflow limitation, those with asthma compared with those without were different both with regard to characteristics and severity of lung disease, suggesting that a vast numbers of individuals with asthma were correctly identified. Additionally, findings were similar even when using LLN as an alternative criterion for defining airflow limitation. Another possible limitation of our study may be that it is difficult to distinguish between asthma and COPD exacerbations as well as pneumonias in a clinical setting. Thus, we only selected the primary discharge diagnosis or the primary cause of death. Although diagnoses recorded in the national registries can only be made by an authorised doctor, we can of course not exclude possible misclassifications.

In conclusion, never-smokers with airflow limitation but without asthma compared with never-smokers with airflow limitation and asthma reported less allergy and respiratory symptoms, and had higher $\mathrm{FEV}_{1}$ and lower levels of eosinophils and IgE. Never-smokers with airflow limitation and asthma compared with never-smokers with airflow limitation but without asthma had an increased risk of asthma and COPD exacerbations, but not of pneumonias. Still, never-smokers with airflow limitation but without asthma had an increased risk of COPD exacerbations and pneumonias, but not of asthma exacerbations compared with never-smokers without airflow limitation or asthma. Thus, our study indicates that the majority of neversmokers with airflow limitation do not seem to have undiagnosed asthma and may instead have airflow limitation caused by other risk factors. Future longitudinal studies should focus on possible risk factors for airflow limitation in this population. Furthermore, our study indicates the need for a multifaceted approach to evaluate respiratory symptoms in never-smoking individuals.

Acknowledgements $Y C$ and SA had full access to all of the data in the study and take responsibility for the integrity of the data and the accuracy of the data analyses. Study concept and design: YÇ, SA, PL and BGN. Acquisition, analyses or interpretation of data: YÇ, SA, PL and BGN. Drafting of the manuscript: YÇ. Critical revision of the manuscript for important intellectual content: $Y C,, S A, P L$ and $B G N$. Statistical analyses: YÇ and SA. Obtained funding: PL and BGN. Administrative, technical or material support: BGN. Study supervision: PL and BGN.

Funding Funded by the Danish Lung Association, the Danish Cancer Society, Department of Clinical Biochemistry and Department of Internal Medicine, Herlev and Gentofte Hospital, Copenhagen University Hospital and Department of Public Health, University of Copenhagen.

Competing interests None declared.

Ethics approval The study was approved by Herlev and Gentofte Hospital and a Danish ethical committee, and was conducted according to the Declaration of Helsinki. Written informed consent was obtained from all participants.

Provenance and peer review Not commissioned; externally peer reviewed. 


\section{REFERENCES}

1 Salvi SS, Barnes PJ. Chronic obstructive pulmonary disease in non-smokers. Lancet 2009;374:733-43.

2 Thomsen M, Nordestgaard BG, Vestbo J, et al. Characteristics and outcomes of chronic obstructive pulmonary disease in never smokers in Denmark: a prospective population study. Lancet Respir Med 2013;1:543-50.

3 Silva GE, Sherrill DL, Guerra S, et al. Asthma as a risk factor for COPD in a longitudinal study. Chest 2004;126:59-65.

4 Vonk JM, Jongepier $\mathrm{H}$, Panhuysen $\mathrm{Cl}$, et al. Risk factors associated with the presence of irreversible airflow limitation and reduced transfer coefficient in patients with asthma after 26 years of follow up. Thorax 2003;58:322-7.

5 Burrows B, Bloom JW, Traver GA, et al. The course and prognosis of different forms of chronic airways obstruction in a sample from the general population. $N$ Eng/ J Med 1987;317:1309-14.

6 de Marco R, Marcon A, Jarvis D, et al. Inhaled steroids are associated with reduced lung function decline in subjects with asthma with elevated total IgE. J Allergy Clin Immunol 2007;119:611-17.

7 Dijkstra A, Vonk JM, Jongepier $H$, et al. Lung function decline in asthma: association with inhaled corticosteroids, smoking and sex. Thorax 2006;61:105-10.

8 James AL, Palmer LJ, Kicic E, et al. Decline in lung function in the Busselton Health Study: the effects of asthma and cigarette smoking. Am J Respir Crit Care Med 2005;171:109-14.

9 Lange $\mathrm{P}$, Parner J, Vestbo J, et al. A 15-year follow-up study of ventilatory function in adults with asthma. N Engl J Med 1998;339:1194-200.

10 Lange $P$, Scharling $H$, Ulrik CS, et al. Inhaled corticosteroids and decline of lung function in community residents with asthma. Thorax 2006;61:100-4.

11 O'Byrne PM, Pedersen S, Lamm CJ, et al. Severe Exacerbations and Decline in Lung Function in Asthma. Am J Respir Crit Care Med 2009;179:19-24.

12 Schachter EN, Doyle CA, Beck GJ. A prospective study of asthma in a rural community. Chest 1984;85:623-30.

13 Ulrik CS, Lange P. Decline of lung function in adults with bronchial asthma. Am J Respir Crit Care Med 1994;150:629-34.

14 Çolak Y, Afzal S, Nordestgaard BG, et al. Characteristics and Prognosis of Never-Smokers and Smokers with Asthma in the Copenhagen General Population Study. A Prospective Cohort Study. Am J Respir Crit Care Med 2015;192:172-81.

15 Lange P, Marott JL, Vestbo J, et al. Prediction of the clinical course of chronic obstructive pulmonary disease, using the new GOLD classification: a study of the general population. Am J Respir Crit Care Med 2012;186:975-81.

16 Bakke PS, Rönmark E, Eagan T, et al. Recommendations for epidemiological studies on COPD. Eur Respir J 2011;38:1261-77.

17 Storm HH, Michelsen EV, Clemmensen IH, et al. The Danish Cancer Registry-history, content, quality and use. Dan Med Bull 1997;44:535-9.

18 Thomsen RW, Lange $\mathrm{P}$, Hellquist $\mathrm{B}$, et al. Validity and underrecording of diagnosis of COPD in the Danish National Patient Registry. Respir Med 2011;105:1063-8.

19 Andersen PK, Gill RD. Cox Regression-Model for Counting-Processes: a Large Sample Study. Annals of Statistics 1982;10:1100-20.

20 Lee KJ, Carlin JB. Multiple imputation for missing data: fully conditional specification versus multivariate normal imputation. Am J Epidemiol 2010;171:624-32.
21 Fish JE, Peters SP. Airway remodeling and persistent airway obstruction in asthma. J Allergy Clin Immunol 1999;104:509-16.

22 Global Strategy for Asthma Management and Prevention. Global Initiative for Asthma (GINA). http://www.ginasthma.org/documents/4 (accessed 9 Dec 2015).

23 Contoli M, Baraldo S, Marku B, et al. Fixed airflow obstruction due to asthma or chronic obstructive pulmonary disease: 5-year follow-up. J Allergy Clin Immunol 2010;125:830-7.

24 Global Strategy for the Diagnosis, Management, and Prevention of Chronic Obstructive Lung Disease. Global Initiative for Chronic Obstructive Lung Disease (GOLD). http://www.goldcopd.org/ guidelines-global-strategy-for-diagnosis-management.html (accessed 9 Dec 2015).

25 Tan WC, Sin DD, Bourbeau J, et al. Characteristics of COPD in never-smokers and ever-smokers in the general population: results from the CanCOLD study. Thorax 2015;70:822-9.

26 Hagstad S, Ekerljung L, Lindberg A, et al. COPD among non-smokers-report from the obstructive lung disease in Northern Sweden (OLIN) studies. Respir Med 2012;106:980-8.

27 Perez-Padilla R, Fernandez R, Lopez Varela MV, et al. Airflow obstruction in never smokers in five Latin American cities: the PLATINO study. Arch Med Res 2012;43:159-65.

28 Miravitlles M, Ferrer M, Pont A, et al. Characteristics of a population of COPD patients identified from a population-based study. Focus on previous diagnosis and never smokers. Respir Med 2005;99:985-95.

29 Bridevaux PO, Probst-Hensch NM, Schindler C, et al. Prevalence of airflow obstruction in smokers and never-smokers in Switzerland. Eur Respir J 2010;36:1259-69.

30 Lamprecht B, Schirnhofer L, Kaiser B, et al. Non-reversible airway obstruction in never smokers: results from the Austrian BOLD study. Respir Med 2008; 102:1833-8.

31 Lange $\mathrm{P}$, Celli $\mathrm{B}$, Agustí $\mathrm{A}$, et al. Lung-function trajectories leading to chronic obstructive pulmonary disease. N Engl J Med 2015;373:111-22.

32 Baughman $P$, Marott JL, Lange $P$, et al. Combined effect of lung function level and decline increases morbidity and mortality risks. Eur J Epidemiol 2012;27:933-43.

33 Kerstjens HA, Rijcken B, Schouten JP, et al. Decline of FEV1 by age and smoking status: facts, figures, and fallacies. Thorax 1997;52:820-7.

34 Knudson RJ, Lebowitz MD, Holberg CJ, et al. Changes in the normal maximal expiratory flow-volume curve with growth and aging. Am Rev Respir Dis 1983;127:725-34.

35 Tager IB, Segal MR, Speizer FE, et al. The natural history of forced expiratory volumes. Effect of cigarette smoking and respiratory symptoms. Am Rev Respir Dis 1988; 138:837-49.

36 Birring SS, Brightling CE, Bradding $\mathrm{P}$, et al. Clinical, radiologic, and induced sputum features of chronic obstructive pulmonary disease in nonsmokers. Am J Respir Crit Care Med 2002;166:1078-83.

37 Toren K, Brisman J, Järvholm B. Asthma and asthma-like symptoms in adults assessed by questionnaires. A literature review. CHEST Journal 1993;104:600-8.

38 Peat JK, Toelle BG, Marks GB, et al. Continuing the debate about measuring asthma in population studies. Thorax 2001;56:406-11. 